\title{
1 Chasing boundaries and cascade effects in a coupled barrier-marsh-lagoon system
}

3 Jorge Lorenzo-Trueba ${ }^{1}$, Giulio Mariotti ${ }^{2,3}$

4 1. Department of Earth and Environmental Studies, Montclair State University, NJ 07043, USA

$5 \quad$ jorge.lorenzo@montclair.edu.

6 2. Department of Oceanography and Coastal Sciences, Louisiana State University, Baton $7 \quad$ Rouge, LA 70803, USA.

9 3. Center for Computation and Technology, Louisiana State University, Baton Rouge, LA 10 70803, USA.

\section{Abstract}

14 The long-term dynamic evolution of an idealized barrier-marsh-lagoon system experiencing sea-

15 level rise is studied by coupling two existing numerical models. The barrier model accounts for

16 the interaction between shoreface dynamics and overwash flux, which allows the occurrence of

17 barrier drowning. The marsh-lagoon model includes both a backbarrier marsh and an interior

18 marsh, and accounts for the modification of the wave regime associated with changes in lagoon

19 width and depth. Overwash, the key process that connects the barrier shoreface with the marsh-

20 lagoon ecosystems, is formulated to account for the role of the backbarrier marsh. Model results

21 show that a number of factors that are not typically associated with the dynamics of coastal

22 barriers can enhance the rate of overwash-driven landward migration by increasing backbarrier

23 accommodation space. For instance, lagoon deepening could be triggered by marsh edge retreat 
24 and consequent export of fine sediment via tidal dispersion, as well as by an expansion of inland

25 marshes and consequent increase in accommodation space to be filled in with sediment. A

26 deeper lagoon results in a larger fraction of sediment overwash being subaqueous, which coupled

27 with a slow shoreface response sending sediment onshore can trigger barrier drowning. We

28 therefore conclude that the supply of fine sediments to the back-barrier and the dynamics of both

29 the interior and backbarrier marsh can be essential for maintaining the barrier system under

30 elevated rates of sea-level rise. Our results highlight the importance of considering barriers and

31 their associated backbarriers as part of an integrated system in which sediment is exchanged.

\section{1. Introduction}

34 Low-lying coasts are often characterized by barrier islands, km-wide stretches of sand separated

35 from the mainland by marshes and lagoons. Barriers commonly serve as buffer zones between

36 the coastal ocean and mainland human population centers and infrastructure, protecting these

37 communities from the most devastating coastal impacts of climate change. Barriers themselves

38 are also some of the most popular tourist and recreational destinations in the US, and constitute

39 some of the most valuable real estate in the country (Heinz-Center, 2000; Morton, 2008).

40 Furthermore, barriers support biodiversity (McLachlan, 1983), provide a range of ecosystem

41 services (Barbier et al., 2010), and protect wetlands that, in turn, support their own diverse

42 ecologies (Day et al., 2008).

43 Despite the economic and ecological importance of barriers, and their extensive presence along

44 the US East and Gulf coasts, there exists a critical gap in understanding how barrier systems

45 respond to coastal change. In particular, there is a poor understanding of the complex barrier-

46 backbarrier interactions, which results in landward migration rates unprecedented in thousands of 
47 years (FitzGerald et al., 2008). In order to fill this gap we build an exploratory numerical model

48 (Murray, 2003) to examine the morphological feedbacks within a barrier-marsh-lagoon system

49 and predict its evolution under projected rates of sea-level rise and sediment supply to the

50 backbarrier environment.

51 Our starting point is a recently developed morphodynamic model (Lorenzo-Trueba and Ashton,

52 2014) that couples shoreface evolution and overwash processes in a dynamic framework. As

53 such, the model is able to capture dynamics not reproduced by morphokinematic models, which

54 advect geometries without specific concern to processes. These dynamics include periodic

55 barrier retreat due to time lags in the shoreface response to barrier overwash, height drowning

56 due to insufficient overwash flux as sea level rises, and width drowning, which occurs when the

57 shoreface response rate is insufficient to maintain the barrier geometry during overwash-driven

58 landward migration. The model, however, does not incorporate dynamic processes landward of

59 the barrier, such as erosion and accumulation of peat and lagoonal sediments, which influence

60 the space available for sediment to accumulate behind the barrier and hence control the island

61 migration rate that is triggered by sea-level rise (Bruun, 1988).

62 The two-way interactions between backbarrier marsh and barrier have been recently explored

63 with GEOMBEST+ (Walters, 2014; Brenner, 2015), a modified version of the GEOMBEST

64 model ( Stolper et al., 2005; Moore et al., 2010). The study highlighted how the backbarrier

65 marsh can slow down the island migration rate by reducing the space available for sediment to

66 fill, and that overwash facilitates the persistence of a stable backbarrier marsh. Additionally,

67 coupling field observations with GEOMBEST+ suggests that sediment overwash allows a

68 narrow marsh to be maintained in a long-lasting alternate state within a range of conditions under

69 which they would otherwise disappear (Walters et al., 2014). Here we propose to further 
70 investigate the evolution of barrier and backbarrier environments by coupling a morphodynamic

71 barrier model (Lorenzo-Trueba and Ashton, 2014) with a dynamic model for the evolution of the

72 marsh platform and the marsh boundary with the adjacent lagoon. In particular, we have

73 extended a model developed by Mariotti and Carr (2014) to include both a backbarrier and an

74 interior marsh, and modified the barrier overwash flux to account for the presence of a

75 backbarrier marsh. The resulting model represents a cross-section that spans from the toe of the

76 shoreface to the point where the marshes encroach the mainland, that is, the upper limit of the

77 marine influence (Fig. 1). This modeling framework allows us to explore new feedbacks between

78 barrier and their backbarrier ecosystems that have not been tackled before.

\section{Coupled model description}

81 Our model approach assumes an idealized cross-section (Fig.1) that connects the shoreface, the

82 barrier, and the backbarrier. The backbarrier, defined here as the region between the barrier and

83 the upper limit of the marine influence, includes three units: a backbarrier marsh (or rear fringing

84 marsh), a lagoon, and an inland marsh. The barrier model component accounts for the interaction

85 between shoreface dynamics and overwash flux, and the marsh-lagoon component explicitly

86 describes marsh edge processes of both the backbarrier marsh and the interior marsh, and

87 accounts for the modification of the wave regime associated with lagoon width, which coincides

88 with the wave fetch.

\section{$89 \quad 2.1$ Barrier dynamics}

90 Our model focuses on two primary barrier system components or behavioral elements: the

91 marine domain represented by the active shoreface, and the backbarrier environment, where the 
92 infrequent process of overwash controls landward mass fluxes. As described in Lorenzo-Trueba

93 and Ashton (2014), the evolution of the barrier system can be fully determined with the rates of

94 migration of the shoreface toe $\dot{x}_{T}=d x_{T} / d t$, the shoreline $\dot{x}_{S}=d x_{S} / d t$, the landward end of the

95 subaerial portion of the barrier $\dot{x}_{B}=d x_{B} / d t$, and the change of the barrier height

$96 \dot{H}=d H / d t$ (Fig. 1). These rates can be written in terms of the sediment flux at the shoreface

$97 Q_{S F}$, the sea-level rise rate $\dot{z}$, the total overwash flux $Q_{O W}$, the top-barrier overwash component

$98 Q_{o W, H}$ and the backbarrier overwash component $Q_{o W, B m}$ (Fig. 1 and 3):

$99 \quad \dot{x}_{T}=4 Q_{S F} \frac{H+D_{T}}{D_{T}\left(2 H+D_{T}\right)}+\frac{2 \dot{z}}{\alpha}$

$100 \quad \dot{x}_{S}=\frac{2 Q_{O W}}{2 H+D_{T}}-4 Q_{S F} \frac{H+D_{T}}{\left(2 H+D_{T}\right)^{2}}$

$101 \quad \dot{x}_{B}=\frac{Q_{O W, B m}}{H+z_{b m}-r / 2}$

$102 \dot{H}=\frac{Q_{O W, H}}{W}-\dot{z}$

103 where $H$ is the barrier height, $W$ is the barrier width, $\alpha$ is the shoreface depth, $D_{T}$ is the shoreface 104 depth, $z_{b m}$ is the backbarrier marsh depth, $r$ is the tidal range, and $\dot{z}$ is the sea-level rise rate (Fig.

105 1). We compute the shoreface and overwash sediment fluxes following Lorenzo-Trueba and 106 Ashton (2014). Shoreface sediment fluxes are determined based upon deviations from an 107 equilibrium profile. When the shoreface slope is shallower than its equilibrium slope, sediment

108 flux at the shoreface is directed onshore. In contrast, when the shoreface slope is steeper than the 109 equilibrium slope, sediment is directed offshore. Additionally, we compute overwash flux using 
110 a simple formulation that relies upon the critical length concept (Leatherman, 1983). This

111 formulation assumes the existence of a critical barrier width $W_{e}$ and a critical barrier height $H_{e}$

112 beyond which overwash flux to the back and the top of the barrier shuts down. When the barrier

113 width $W$ and height $H$ are below their critical values, the overwash rates $Q_{O W, H}$ and $Q_{O W, B}$ scale

114 with their associated deficit volumes, $V_{d, B}$ and $V_{d, H}$ (Fig.2). Lorenzo-Trueba and Ashton (2014)

115 considered a lagoon in the backbarrier and defined the backbarrier deficit volume as

$116 V_{d, B}=\max \left[0,\left(W_{e}-W\right)\left(H+z_{L}-r / 2\right)\right]$. Here, in order to account for the presence of a backbarrier

117 marsh, we substitute the lagoon depth with a linear combination of the backbarrier marsh depth

$118 z_{b m}$, and the lagoon depth $z_{L}$ :

$119 V_{d, B}=\max \left[0,\left(W_{e}-W\right)\left(H+\phi\left(z_{b m}-r / 2\right)+(1-\phi)\left(z_{L}-r / 2\right)\right]\right.$

120 where:

$121 \phi=\min \left(1, \frac{b_{b m}}{b_{b m c}}\right)$

122 This formulation is clarified by considering its two end members. When the backbarrier marsh

123 width, $b_{b m}$, is larger than the critical barrier marsh width, $b_{b m c}$, i.e., $\phi=1$, overwash sediment is

124 unable to reach the lagoon, and thus, only the backbarrier marsh depth $z_{b m}$ is involved in the

125 deficit volume calculation. In contrast, when the backbarrier marsh disappears, i.e., $\phi=0$, only

126 the lagoon depth $z_{L}$ affects the deficit volume calculation, and the model recovers the

127 formulation introduced by Lorenzo-Trueba and Ashton (2014). Thus, this formulation implies

128 that the presence of marsh ecosystems reduces backbarrier accommodation (Fig. 2), which in

129 turn reduces the backbarrier overwash flux (Bruun, 1988). Additionally, for intermediate values

130 of the backbarrier marsh width (i.e., $0<\phi<1$ ), the backbarrier deficit volume depends on both the 
131 marsh and the lagoon elevations (see equation 5). In this intermediate case, sediment overwash

132 can reach both the backbarrier marsh and the lagoon. Consequently, we extend the overwash

133 formulation presented by Lorenzo-Trueba and Ashton (2014) to account for two backbarrier

134 overwash components: a backbarrier marsh overwash flux $Q_{O W, B m}$, which contributes to the

135 progradation of the barrier over the backbarrier marsh (Fig. 3), and a lagoon overwash flux

$136 Q_{O W, B l}$, which contributes to the progradation of the backbarrier marsh (Fig. 3). We compute

137 these fluxes as follows:

$138 Q_{O W, B l}=(1-\phi) Q_{O W, B}$

$139 Q_{O W, B m}=\phi Q_{O W, B}$

140 Hence, when the backbarrier marsh is very wide, the overwash flux does not reach the lagoon 141 and thus does not contribute to the progradation of the backbarrier marsh (i.e., $Q_{O W, B l}=0$ ). In 142 contrast, when the backbarrier marsh disappears, the backbarrier overwash flux $Q_{\text {ow,B }}$ 143 contributes to the landward migration of the barrier (Fig. 3). Additionally, for intermediate 144 values of the backbarrier marsh width, overwash flux contributes to both the landward migration 145 of the barrier and the backbarrier marsh (Fig. 3). In particular, we note that a narrow marsh will 146 prograde faster than a wider marsh due to a larger overwash sediment input (equations (6) to 147 (8)), which allows for the tendency of a narrow backbarrier marsh to persist. In this way, under 148 the right conditions an equilibrium state for the backbarrier marshes can emerge (see section 149 3.2), a dynamic that has been previously described by Walters et al. (2014).

150 We note that this formulation of overwash deposition is partly constrained by the imposed 151 geometry of the system (Fig. 1), and therefore differs from the one implemented in 152 GEOMBEST+ (Walters et al., 2014), in which vertical accretion rates vary with distance from 153 the barrier. However, although this formulation oversimplifies the complex process of barrier 
154 overwash, it is consistent with the 'critical barrier width' concept introduced by Leatherman

155 (1983), as well as many subsequent numerical implementations to study the long-term evolution

156 of barriers and the shoreline (Jiménez and Sánchez-Arcilla, 2004; McNamara and Werner,

157 2008). Additionally, we note that the general model framework is flexible such that it could also

158 incorporate different approaches to computing overwash flux.

\subsection{Marsh-lagoon dynamics}

160 The dynamics of the backbarrier environment can be fully described with the rates of change of

161 the depth of the lagoon $\dot{z}_{L}=d z_{L} / d t$, backbarrier marsh $\dot{z}_{b m}=d z_{b m} / d t$, and interior marsh

$162 \dot{z}_{\text {im }}=d z_{\text {im }} / d t$, and the rates of change of the backbarrier marsh edge $\dot{x}_{b m}=d x_{b m} / d t$, interior marsh

163 edge $\dot{x}_{i m}=d x_{i m} / d t$, and the boundary between the interior marsh and mainland $\dot{x}_{m m}=d x_{m m} / d t$.

164 The horizontal migration of the two marsh boundaries is controlled by the competition by wave 165 erosion and sediment accretion (Mariotti and Fagherazzi, 2013; Mariotti and Carr, 2014). Thus,

166 both erosion rates $E_{b m}$ and $E_{i m}$, and progradation rates $P_{b m}$ and $P_{i m}$, on each side of the lagoon,

167 depend on the reference wind speed, the width and depth of the lagoon, the depth of the marsh,

168 and the sediment concentration in the lagoon. In addition, the backbarrier marsh receives the

169 overwash flux $Q_{o w, B l}$, and hence the equations read:

$170 \quad \dot{x}_{b m}=P_{b m}-E_{b m}+\frac{Q_{O W, B l}}{z_{L}-z_{b m}}$

$171 \quad \dot{x}_{i m}=E_{i m}-P_{i m}$

172 The variations in height of the two marshes are controlled by the sea-level rise rate, the organic

173 accretion rates $O_{b m}$ and $O_{i m}$, and the inorganic sediment flux from the lagoon to the backbarrier 
174 marsh $I_{b m}$ and the inland marsh $I_{i m} \cdot I_{b m}$ and $I_{i m}$ are computed through the tidal dispersion

175 mechanism as a function of the reference sediment concentrations in the lagoon and each of the 176 marshes (Mariotti and Carr, 2014):

$177 \quad \dot{z}_{b m}=-I_{b m}-O_{b m}+\dot{z}$

$178 \quad \dot{z}_{i m}=-I_{i m}-O_{i m}+\dot{z}$

179 Both $O_{b m}$ and $O_{i m}$ are assumed to be proportional to refractory component of the annual below 180 ground organic matter production (Mudd et al., 2009; Mariotti and Carr, 2014). Additionally, 181 following Morris et al. (2002), both $O_{b m}$ and $O_{i m}$ are computed as a quadratic function of the 182 depth of inundation respect to mean high tide (Morris et al., 2002).

183 The migration of the inland marsh towards mainland is simply controlled by the height of the 184 interior marsh and the slope of the underlying landscape (Fig. 1):

$185 \quad \dot{x}_{m m}=\frac{\dot{z}-\dot{z}_{i m}}{\beta}$

186 Finally, the variations of the lagoon depth depend on the balance between the horizontal flux at

187 the marsh boundary, the sediment flux from the lagoon to the marsh platform, and the exchange

188 between open ocean and lagoon, $I_{o l}$ ( Mariotti and Fagherazzi, 2013; Mariotti and Carr, 2014):

$189 \dot{z}_{L}=I_{b m} \frac{b_{b m}}{b_{L}}+I_{i m} \frac{b_{i m}}{b_{L}}+I_{o l}-\left(E_{b m}-P_{b m}\right) \frac{z_{L}-z_{b m}}{b_{L}}-\left(E_{i m}-P_{i m}\right) \frac{z_{L}-z_{i m}}{b_{L}}+\dot{z}$

190 The exchange between lagoon and the open ocean is a key driver of the dynamics of the lagoon,

191 and depends on the balance between sediment export and import. Sediment export is set

192 proportional to the reference sediment concentration in the lagoon $C_{r}$, which is determined by 
193 wave resuspension. Sediment import is set proportional to the external sediment concentration $C_{0}$

194 , (Mariotti and Carr, 2014), which simulates the availability of fine sediment in the nearshore 195 region (Bartholdy and Anthony, 1998; Bartholdy, 2000).

\subsection{Model Solution}

199 The evolution of the coupled barrier-marsh-lagoon-marsh system is fully determined by the rates 200 of change of the shoreface toe position $\dot{x}_{T}$, the shoreline position $\dot{x}_{S}$, the landward end of the 201 subaerial portion of the barrier $\dot{x}_{B}$, the barrier height $\dot{H}$, the depth of the lagoon $\dot{z}_{L}$, backbarrier

202 marsh elevation $\dot{z}_{b m}$, interior marsh elevation $\dot{z}_{i m}$, the backbarrier marsh edge $\dot{x}_{b m}$, the interior 203 marsh edge position $\dot{x}_{i m}$, and upland marsh edge position $\dot{x}_{m m}$. Combining the barrier and

204 backbarrier processes described in previous section, the evolution of these ten state variables 205 over time is described by equations (1) to (4) and (9) to (14).

206 We numerically solve these equations using a simple Eulerian scheme $\xi=\xi^{\text {old }}+\dot{\xi} \Delta t$, where $207 \xi=x_{T}, x_{S}, x_{B}, H, x_{b m}, x_{i m}, x_{m m}, z_{b m}, z_{i m}, z_{L}$. Key input parameter values are listed in Tables 1 208 and 3; a detailed description of all barrier parameters is included in Lorenzo-Trueba and Ashton 209 (2014), and parameters related to the marsh-lagoon system are included in Mariotti and Carr 210 (2014). As initial barrier geometry (see Fig. 1) we choose:

$212 \alpha(t=0)=\alpha_{e}, W(t=0)=W_{e}, H(t=0)=H_{e}$, and $Z(t=0)=D_{T}$ 
213 This initial geometry is at static equilibrium (i.e., $\dot{x}_{T}=\dot{x}_{S}=\dot{x}_{B}=\dot{H}=0$ ) for a constant sea

214 level (with corresponding zero shoreface and overwash flux). As initial lagoon, backbarrier

215 marsh and inland marsh widths (see Fig. 1) we choose:

216

$217 \quad b_{L}(t=0)=b_{L, 0}, b_{b m}(t=0)=b_{b m, 0}, b_{i m}(t=0)=b_{i m, 0}$

218 The values for $b_{L, 0}, b_{b m, 0}$, and $b_{i m, 0}$ vary between model runs. Their specific values in each figure

219 are included in Table 2. As initial lagoon, backbarrier marsh and inland marsh depths respect to

220 Mean High Water (see Fig. 1) level we choose:

$221 z_{b m}(t=0)=z_{b m, 0}, z_{i m}(t=0)=z_{i m, 0}$ and $z_{L}(t=0)=z_{L, 0}$

222 where $z_{b m, 0}=z_{i m, 0}=0.26 \mathrm{~m}$, and $z_{L, 0}=2 \mathrm{~m}$, which are typical values along the Atlantic and Gulf

223 Coasts.

224

225 3. Results

226

227 Given that the model has nine dynamic variables (Table 1), exploring all the possible

228 combination of parameters and initial conditions is not feasible or useful. In this work, we

229 instead focus on two major aspects that the model is able to capture: the effect of the backbarrier

230 environment (marshes, lagoon, and mainland) on barrier evolution, and the detailed evolution of

231 the backbarrier marsh.

232

233

\subsection{Effect of marsh-lagoon dynamics on barrier evolution}


234 We first analyze changes in barrier evolution under different lagoon geometries, supply of fine

235 sediment to the backbarrier, as well as different rates of inland marsh expansion towards the

236 mainland. Unless otherwise specified, the parameters for these simulations are given in Table 1.

237 3.1.1 Lagoon geometry

238 In order to analyze the effect of lagoon geometry on barrier response, we present two different

239 model runs that only differ in their initial lagoon width (Fig. 4). Additionally, we limit the rate of

240 inland marsh migration towards mainland by imposing a vertical slope at the landward boundary

241 of the basin. In the next section, we relax this condition and explore its effect on the overall

242 behavior.

243 We first consider the scenario in which $b_{L, 0}=5 \mathrm{~km}$. As sea level rises and overwash flux

244 activates, the barrier narrows and migrates landwards. The backbarrier marsh shrinks as the rate

245 of barrier migration exceeds the rate of backbarrier marsh expansion on the lagoon side. Both the

246 lagoon width and depth initially increase, indicating that a width of $5 \mathrm{~km}$ is above the critical

247 value required for marsh erosion to exceed marsh progradation, and sediment resuspension in the

248 lagoon to exceed sedimentation (Mariotti and Fagherazzi, 2013). This trend eventually reverses

249 as barrier migration reduces lagoon fetch, which in turn weakens the wind-wave regime, and

250 favors settling of lagoon sediment over resuspension. In this case the import of sediment from

251 the open ocean to the lagoon (the term $I_{o l}$ in equation 14) overwhelms the tendency to export

252 sediment. Additionally, after a response time lag in which shoreface sediment fluxes are directed

253 offshore, onshore sediment fluxes result in barrier widening on the ocean side, which reduces

254 overwash flux and allows even more barrier widening. Despite the changes in the barrier and

255 lagoon geometries, the backbarrier marsh eventually attains a fixed width, which is consistent

256 with the stable narrow state for the backbarrier marsh introduced by Walter et al. (2014). 
258 A larger lagoon width $\left(b_{L, 0}=30 \mathrm{~km}\right)$ is associated with larger waves, which cause faster retreat of

259 the inland marsh boundary and larger sediment resuspension in the lagoon. As the concentration

260 of sediment in suspension in the lagoon increases with respect to the sediment concentration in

261 the open sea, sediment export via tidal dispersion is enhanced. Such sediment loss results in

262 more lagoon deepening (increasing accommodation), which increases the fraction of sediment

263 overwash being subaequous instead of subaerial (Fig. 3). Such a reduction in overwash sediment

264 to the subaerial portion of the barrier, together with shoreface fluxes that are not able to maintain

265 the barrier geometry during such rapid migration, results in barrier drowning. Due to the high

266 supply of overwash sediment, however, the backbarrier marsh is able to keep up with sea-level

267 rise and the fast migration of the barrier before the barrier drowns.

$269 \quad 3.1 .2$ Sediment supply to the lagoon

270 In this section, we explore how changes in external supply, simulated through the sediment

271 concentration in the open ocean, $C_{0}$, can affect barrier response to sea-level rise. To this end, in

272 Fig. 5 we present three different model runs that only differ in their sediment concentration in the

273 open ocean: $C_{0}=0,30$, and $200 \mathrm{mg} / \mathrm{l}$. These values are in range with field measurements from

274 the Danish Wadden Sea (Bartholdy and Anthony, 1998; Pedersen and Bartholdy, 2006), and with 275 model estimates from Cape May (NJ, USA) (0-20 mg/l) and the Virginia Coastal Reserve (VA, 276 USA) (25-300 mg/l) (Mariotti and Fagherazzi, 2013).

$278 C_{0}$ directly affects the net sediment exchange between the lagoon and the open sea, $I_{o l}$, which is 279 computed through the tidal dispersion mechanism. With a low external sediment supply $\left(C_{0}=0\right)$, 
280 the export of fine sediment from the lagoon to the open ocean increases, leading to a decline in

281 lagoon sedimentation and lagoon deepening. This increase in backbarrier accommodation results

282 in a larger subaqueous fraction of the storm overwash, which leads to barrier narrowing and

283 faster barrier migration, and an enhancement of the wind-wave regime. The combination of these

284 two factors results in the collapse of both the backbarrier and inland marsh. As the barrier

285 continues its landward migration, however, lagoon fetch and wave energy are reduced.

286 Additionally, as the barrier narrows, overwash flux from the shoreface start to reach the lagoon.

287 This supply of overwash sediment to the backbarrier together with the reduction in wave erosion

288 allow the backbarrier marsh to develop again. Despite the expansion of the backbarrier marsh,

289 however, the shoreface response is not fast enough to maintain the barrier width and drowning

290 takes place.

291 An increase in sediment import (e.g., $C_{0}=30 \mathrm{mg} / \mathrm{l}$ ) reduces lagoon deepening, and allows the

292 barrier system to keep up with sea-level rise. During its migration the barrier experiences width

293 oscillations due to time lags in the shoreface response, as previously identified in the barrier

294 model (Lorenzo-Trueba and Ashton, 2014). The backbarrier marsh width also fluctuates due to

295 the associated oscillations in overwash flux.

297 A very large import of sediment to the lagoon (e.g., $C_{0}=200 \mathrm{mg} / \mathrm{l}$ ) drastically changes the

298 barrier-backbarrier dynamics. The lagoon depth initially increases, which indicates that the initial

299 lagoon geometry allows sediment resuspension in the lagoon to exceed sedimentation (Mariotti

300 and Fagherazzi, 2013). This trend, however, soon reverses as lagoon sedimentation is favored

301 and lagoon depth starts to decrease. Backbarrier and inland marsh progradation toward the

302 lagoon is also favored, and leads to a reduction in the lagoon width. This reduction in lagoon 
303 width weakens the wind-wave regime, which in turn reduces marsh edge erosion. This feedback

304 causes the lagoon to fill in and the barrier to migrate more slowly. These results suggest that

305 processes controlling the dynamics of lagoons, such as external mud supply, play a strong role

306 on the fate of the barrier island: marsh ecosystems that experience export rather than import of

307 muddy sediments from the open sea are more prone to retreat and drowning.

$309 \quad$ 3.1.3 Rate of inland marsh expansion

310 The mainland slope $\beta$ controls the rate at which the inland marsh expands landward. In pristine

311 systems, $\beta$ is generally very mild, and allows inland marsh migration into the adjacent uplands as

312 sea level rises (Kirwan et al., 2016). However, in many cases marsh migration is constrained by

313 human structures such as seawalls, dykes or revetments (Feagin et al., 2010; Kirwan et al., 2016;

314 Raabe and Stumpf, 2016). To better understand the effect of such constraints on barrier response,

315 we focus on two scenarios. In the first scenario, we prevent marsh expansion towards land by

316 assuming a vertical mainland slope (i.e., $\beta>>>$ ), which is the same condition that we have used in

317 the previous model runs. In the second scenario, we relax this constraint by assuming a gentle

318 mainland slope (i.e., $\beta=10^{-4}$ ).

319 If marsh expansion towards land is prevented (i.e., $\beta>>>$ ), the barrier response to sea-level rise

320 and overwash is to narrow and migrate landward. The high rates of marsh erosion initially lead

321 to lagoon expansion, which enhances wave activity and triggers lagoon deepening. Eventually,

322 however, marsh erosion diminishes as overwash flux triggers backbarrier marsh progradation. As

323 the landward migration of the barrier continues, this trend reverses and allows onshore sediment

324 fluxes to restore the barrier width. 
325 The dynamics of the lagoon and the barrier changes when the inland marsh is allowed to expand

326 landward (i.e., $\beta=10^{-4}$ ). As the inland marsh expands and covers a larger area, it requires a

327 higher supply of sediment from the lagoon, even if the rate of sea-level rise remains constant.

328 The inland marsh effectively becomes a sink of lagoon sediment, the consequence of which is a

329 deepening of the lagoon. Under these conditions, a larger overwash flux is required to fill an

330 increasing backbarrier accommodation space, which leads to fast barrier migration and

331 eventually barrier drowning if the onshore directed fluxes are insufficient. The landward

332 migration of the inland marsh could therefore, through a cascade of effects, trigger barrier

333 drowning.

\subsection{Backbarrier marsh dynamics}

336 Changes in the width and height of the backbarrier marsh are driven by processes from both the

337 ocean and the lagoon sides (Fig. 7). Storm-driven overwash from the ocean side typically results

338 in backbarrier marsh expansion towards the lagoon (equation 9) (Walters et al., 2014; Walters

339 and Kirwan, 2016), but it can also bury the portion of the marsh closer to the island, which

340 results in the migration of the landward end of the barrier onto the marsh (Eq. 3). Wind waves in

341 the lagoon are important drivers of marsh retreat, whereas accumulation of lagoon sediments in

342 front of the marsh leads to marsh progradation toward the lagoon (Mariotti and Fagherazzi,

343 2013). In this section, we explore the different parameters that control these processes and

344 therefore determine the evolution of the backbarrier marsh.

345 Sea-level rise rate and external sediment concentration are key factors determining whether the

346 backbarrier marsh drowns, expands, contracts, attains a constant width, or squeezes (Fig. 8a).

347 Marsh drowning occurs under high rates of sea-level rise and low lagoon sediment 
concentrations. Under these conditions, the feedback between flooding duration and reduced

349 organic matter accumulation eventually results in marsh being unable to vertically keep up with

350 sea-level rise (Morris et al., 2002). Marsh expansion often occurs under low sea-level rise rates

351 and high lagoon sediment concentrations, although sediment input from rivers can also be an

352 important contributor (Vogel et al., 1996). In these circumstances, the backbarrier marsh tends to

353 prograde into the lagoon, which reduces backbarrier accommodation space and lowers the rate of

354 barrier migration (Fig.3). When the rate of marsh progradation exceeds the rate of barrier

355 migration, the width of the marsh increases (Fig. 8c). In contrast, when the barrier retreats faster

356 than the rate of marsh progradation toward the lagoon, the marsh undergoes width contraction.

357 Because the overwash flux to the marsh edge increases as the marsh width decreases (Fig.3),

358 marsh contraction could halt when the marsh becomes very narrow, and an equilibrium condition

359 in which marsh edge progradation balances barrier migration is attained (Fig. 8c). If the marsh

360 progradation rate, even with the aid of the overwash flux, is smaller than the barrier migration

361 rate, then the marsh contracts and eventually disappears. If the marsh edge retreats instead of

362 prograding, then the marsh is squeezed from both ends: the barrier side and the lagoon side. This

363 condition, which we define as "barrier squeeze" (Figs.8b, 8d), is the most deleterious, and leads

364 to the fastest rate of marsh loss.

366 These results emphasize how overwash flux can be essential to explain changes in the width of

367 the backbarrier marsh. In particular, overwash flux plays a dominant role under low lagoon

368 sediment concentrations, when barrier migration rates and erosion by locally-generated waves

369 are typically high. Under these conditions, a reduction in the maximum overwash flux results in

370 the squeeze of the backbarrier marsh until its eventual disappearance (Fig. 8d). These results 
371 support recent work suggesting that overwash flux provides an essential supply of inorganic

372 sediment, which allows a minimum backbarrier marsh width to be maintained under high rates of

373 sea-level rise (Rodriguez et al., 2013; Walters et al., 2014).

\section{4. Discussion and implications}

378 Model results presented in this manuscript are not intended to specifically reproduce the

379 evolution of any particular coastal system but to reveal the coupling between the barrier and its

380 backbarrier environments. This approach implies that processes that could affect the response of

381 the coupled system are purposely omitted from this version of the model. For instance, the model

382 presented here assumes that the barrier is composed of uniform grain-size and non-cohesive 383 sediment. The effect of non-sandy lithology outcrops at the shoreface, however, can also alter the 384 response of the coupled system (Brenner et al., 2015). In particular, muddy sediments deposited 385 in the backbarrier environment that will later outcrop on the shoreface do not contribute to the 386 sand volume as the barrier migrates landwards. As discussed by Brenner et al. (2015), such 387 reduction in coarse sediment maintaining the barrier could significantly enhance barrier 388 drowning.

390 The model does not account for changes in backbarrier hypsometry, which can affect the 391 sediment dispersal along the barrier complex (Georgiou et al., 2005). Additionally, inland and 392 backbarrier marsh environments are characterized with an average elevation with respect to 393 mean sea level, which does not allow for the presence of different plant species. Future modeling 
394 efforts will aim to dynamically account for the long-term evolution of both low and high marshes

395 in the backbarrier environment.

397 Furthermore, the model does not incorporate the effect of alongshore gradients, spit formation,

398 barrier breaching and inlet closure, or ebb and flood tidal delta sediment dynamics. Current

399 modeling efforts, however, aim at incorporating these effects. In particular, the barrier model

400 component has recently been extended to account for both the alongshore and cross-shore

401 transport directions (Ashton and Lorenzo-Trueba, 2015).

402

403 Leaving out many of the processes operating in a complex system such as a barrier-marsh-lagoon

404 environment can potentially increase the clarity and insights the model facilitates (Murray,

405 2003), and therefore highlight the importance of considering barriers and their associated

406 backbarriers as part of an integrated system in which sediment is exchanged. In particular, model

407 results demonstrate that factors such as lagoon geometry, export of fine sediments from the

408 lagoon to the open ocean, and the slope of mainland, which are typically not directly related to

409 barrier evolution, could play a major effect on the long-term barrier response to sea-level rise.

410 Moreover, model results presented here suggest that the supply of sediments (particularly muddy

411 sediment) to the lagoon can not only help repair marsh environments, but also slow down the

412 rate of barrier migration and potentially reduce the risk of future barrier drowning. Future

413 modeling efforts will span a wider range of scenarios and parameter values to explore whether an

414 increase in sediment supply in the backbarrier has always the same effect. 
416 This coupled system approach is particularly important when seeking to maximize the resilience

417 of coastal communities to predicted increases in storm intensity (Emanuel, 2013), and a rising

418 mean sea level (IPCC, 2014), which increases the impact of storm events (Tebaldi et al., 2012).

419 Yet, restoration activities often follow a compartmental approach, where the focus is limited to a 420 very small part of a large system. For example, marsh restoration activities, such as de-

421 embankment of previously reclaimed salt-marsh land, opening anthropogenic dikes, (re)creating

422 tidal channels, vegetating intertidal dredge disposal, nutrient flux modifications, and hardening

423 marsh shorelines to prevent marsh edge erosion (Weinstein et al., 2001; Teal and Weishar, 2005;

424 Wolters et al., 2005), generally do not account for their consequences on barrier islands. 425 Additionally, billions of dollars are spent on barrier stabilization efforts such as beach 426 nourishment practices, jetties, groins, or sea walls (Titus et al., 1991; NAP, 1995; Trembanis et 427 al., 1999). Such barrier stabilization efforts may serve to protect vulnerable barrier communities, 428 but are commonly undertaken without full understanding of the potential impacts on associated 429 backbarrier ecosystems. For instance, anthropogenic structures on barrier islands can limit the 430 landward extent and volume of overwash deposition relative to a nearby natural area (Rogers et 431 al., 2015). This reduction of inorganic sediment supply to the backbarrier marsh can, in turn, 432 diminish backbarrier marsh resilience to wave erosion (Fig. 8).

\section{Acknowledgements}

437 This manuscript is the result of research sponsored by the New Jersey Sea Grant Consortium 438 (NJSGC) with funds from the National Oceanic and Atmospheric Administration (NOAA) 
Office of Sea Grant, U.S. Department of Commerce, under NOAA grant number 6610-0006 and

440 the NJSGC. The statements, findings, conclusions, and recommendations are those of the

441 author(s) and do not necessarily reflect the views of the NJSGC or the U.S. Department of

442 Commerce. Department of Commerce. NJSG-17-910. Additionally, the authors want to thank to

443 Brad Murray and an anonymous reviewer for their constructive reviews, and Andy Plater for

444 editing the manuscript.

Tables

Table 1. Description of key barrier input parameters. A more detailed description of all the

451 parameters related to the barrier system is included in Lorenzo-Trueba and Ashton (2014).

\begin{tabular}{|l|l|c|} 
Symbol & Meaning & Units \\
\hline$D_{T}$ & depth of the shoreface toe & $\mathrm{L}$ \\
$\dot{z}$ & relative sea-level rise rate & $\mathrm{L} / \mathrm{T}$ \\
$W_{e}$ & critical barrier width & $\mathrm{L}$ \\
$H_{e}$ & critical barrier height & $\mathrm{L}$ \\
$\alpha_{e}$ & shoreface slope at static equilibrium & - \\
$K$ & shoreface response rate & $\mathrm{L}^{3} / \mathrm{L} / \mathrm{T}$ \\
$Q_{O W, \max }$ & maximum overwash sediment flux & $\mathrm{L}^{3} / \mathrm{L} / \mathrm{T}$ \\
$V_{d, \max }$ & maximum deficit volume & $\mathrm{L}^{3} / \mathrm{L}$
\end{tabular}

453 Table 2. Barrier input parameter values used in Figures 4 to 8.

\begin{tabular}{|l|l|l|l|l|l|l|l|l|} 
Figure & $\begin{array}{l}D_{T} \\
(m)\end{array}$ & $\begin{array}{l}\dot{z} \\
(m m / y)\end{array}$ & $\begin{array}{l}W_{e} \\
(m)\end{array}$ & $\begin{array}{l}H_{e} \\
(m)\end{array}$ & $\begin{array}{l}\alpha_{e} \\
(-)\end{array}$ & $\begin{array}{l}K \\
\left(m^{3} / m / y\right)\end{array}$ & $\begin{array}{l}Q_{O W, \text { max }} \\
\left(m^{3} / m / y\right)\end{array}$ & $\begin{array}{l}V_{d, \max } \\
\left(m^{3} / m\right)\end{array}$ \\
\end{tabular}




\begin{tabular}{|l|l|l|l|l|l|l|l|l|}
\hline 4 & 10 & 5 & 800 & 2 & 0.02 & 2,000 & 100 & $H_{e} \cdot W_{e}$ \\
5 & 10 & 5 & 800 & 2 & 0.02 & 2,000 & 100 & $H_{e} \cdot W_{e}$ \\
6 & 10 & 5 & 800 & 2 & 0.02 & 2,000 & 100 & $H_{e} \cdot W_{e}$ \\
8 & 10 & varies & 800 & 2 & 0.02 & 2,000 & varies & $H_{e} \cdot W_{e}$
\end{tabular}

455 Table 3. Description of key backbarrier parameters used in Figures 4 to 8. A more detailed 456 description of all parameters related to the marsh-lagoon system are included in Mariotti and 457 Carr (2014).

\begin{tabular}{|l|l|c|} 
Symbol & Meaning & Units \\
\hline$\beta$ & mainland slope & - \\
$C_{0}$ & sediment concentration in open ocean & $\mathrm{L}^{3} / \mathrm{L}$ \\
$r$ & tidal range & $\mathrm{L}$ \\
$P$ & tidal period & $\mathrm{T}$ \\
$w_{s}$ & settling velocity of lagoon sediment & $\mathrm{L} / \mathrm{T}$ \\
$U$ & wind speed & $\mathrm{L} / \mathrm{T}$ \\
$B_{p e a k}$ & peak biomass & $\mathrm{M} / \mathrm{L}^{2}$ \\
$b_{b m, 0}$ & Initial backbarrier marsh width & $\mathrm{L}$ \\
$b_{i m, 0}$ & Initial inland marsh width & $\mathrm{L}$ \\
$b_{L, 0}$ & Initial lagoon width & $\mathrm{L}$ \\
$b_{b m c}$ & Critical backbarrier marsh width & $\mathrm{L}$
\end{tabular}

461 Table 4. Barrier input parameter values used in Figures 6 to 8.

\begin{tabular}{|l|l|l|l|l|l|l|l|l|l|l|l|} 
Figure & $b_{b m, 0}$ & $b_{i m, 0}$ & $b_{L, 0}$ & $b_{b m c}$ & $\beta$ & $C_{0}$ & $r$ & $P$ & $w_{s}$ & $U$ & $B_{\text {peak }}$ \\
$(\mathrm{km})$ & $(\mathrm{km})$ & $(\mathrm{km})$ & $(\mathrm{km})$ & $(-)$ & $(m g / l)$ & $(m)$ & $(h)$ & $(\mathrm{mm} / \mathrm{s})$ & $(\mathrm{m} / \mathrm{s})$ & $\left(k g / \mathrm{m}^{2}\right)$ \\
& & & & & & & & \\
\end{tabular}




\begin{tabular}{|l|l|l|l|l|l|l|l|l|l|l|l|}
4 & 1 & 2 & varies & 1 & vertical & 30 & 1.4 & 12.5 & 0.5 & 10 & 2.5 \\
5 & 1 & 2 & 10 & 1 & vertical & varies & 1.4 & 12.5 & 0.5 & 10 & 2.5 \\
6 & 1 & 2 & 20 & 1 & varies & 20 & 2 & 12.5 & 0.5 & 10 & 2.5 \\
8 & 1 & 2 & 10 & 1 & vertical & varies & 1.4 & 12.5 & 0.5 & 10 & 2.5
\end{tabular}

\section{References}

Ashton, A.B., Lorenzo-Trueba, J., 2015. Complex responses of barriers to sea-level rise emerging from a model of alongshored-coupled dynamic profile evolution, Coastal Sediments San Diego, USA.

Barbier, E.B., Hacker, S.D., Kennedy, C., Koch, E.W., Stier, A.C., Silliman, B.R., 2010. The value of estuarine and coastal ecosystem services. Ecol. Monogr., 81(2), 169-193.

Bartholdy, J., 2000. Processes controlling import of fine-grained sediment to tidal areas: a simulation model. Geological Society, London, Special Publications, 175(1), 13-29.

Bartholdy, J., Anthony, D., 1998. Tidal dynamics and seasonal dependent import and export of finegrained sediment through a back-barrier tidal channel of the Danish Wadden Sea, Tidal Sedimentology, Modern and Ancient. SEPM Special Publication, pp. 43-52.

Brenner, O.T., Moore, L.J., Murray, A.B., 2015. The complex influences of back-barrier deposition, substrate slope and underlying stratigraphy in barrier island response to sea-level rise: Insights from the Virginia Barrier Islands, Mid-Atlantic Bight, U.S.A. Geomorphology, 246, 334-350.

Bruun, P., 1988. The Bruun rule of erosion: a discussion on large-scale two and three dimensional usage. J. Coastal Res., 4, 626-648.

Day, J.W., Christian, R.R., Boesch, D.M., Yanez-Arancibia, A., Morris, J., Twilley, R.R., Naylor, L., Schaffner, L., Stevenson, C., 2008. Consequences of climate change on the ecogeomorphology of coastal wetlands. Estuaries Coasts, 31(3), 477-491.

Emanuel, K.A., 2013. Downscaling CMIP5 climate models shows increased tropical cyclone activity over the 21st century. Proc. Nat. Acad. Sci., 110(30), 12219-12224.

Feagin, R.A., Martinez, M.L., Mendoza-Gonzalez, G., Costanza, R., 2010. Salt marsh zonal migration and ecosystem service change in response to global sea level rise: a case study from an urban region.

FitzGerald, D.M., Fenster, M.S., Argow, B.A., Buynevich, I.V., 2008. Coastal impacts due to sea-level rise, Annu. Rev. Earth Planet. Sci. Annual Review of Earth and Planetary Sciences. Annual Reviews, Palo Alto, pp. 601-647.

Georgiou, I.Y., FitzGerald, D.M., Stone, G.W., 2005. The Impact of Physical Processes along the Louisiana Coast. J. Coastal Res., 72-89.

Heinz-Center, 2000. The hidden costs of coastal hazards: Implications for risk assessment and mitigation. Island Press.

IPCC, 2014. Climate Change 2014-Impacts, Adaptation and Vulnerability: Regional Aspects. Cambridge University Press. 
Jiménez, J.A., Sánchez-Arcilla, A., 2004. A long-term (decadal scale) evolution model for microtidal barrier systems. Coast Eng., 51(8-9), 749-764.

Kirwan, M.L., Walters, D.C., Reay, W.G., Carr, J.A., 2016. Sea level driven marsh expansion in a coupled model of marsh erosion and migration. Geophysical Research Letters, 43(9), 2016GL068507.

Leatherman, S.P., 1983. Barrier dynamics and landward migration with Holocene sea-level rise. Nature, 301(3 February), 415-417.

Lorenzo-Trueba, J., Ashton, A.D., 2014. Rollover, drowning, and discontinuous retreat: Distinct modes of barrier response to sea-level rise arising from a simple morphodynamic model. Journal of Geophysical Research: Earth Surface, 119(4), 2013JF002941.

Mariotti, G., Carr, J., 2014. Dual role of salt marsh retreat: Long-term loss and short-term resilience. Water Resources Research, 50(4), 2963-2974.

Mariotti, G., Fagherazzi, S., 2013. Critical width of tidal flats triggers marsh collapse in the absence of sea-level rise. Proc. Nat. Acad. Sci., 110(14), 5353-5356.

McLachlan, A., 1983. Sandy Beach Ecology - A Review. In: A. McLachlan, T. Erasmus (Eds.), Sandy Beaches as Ecosystems. Developments in Hydrobiology. Springer Netherlands, pp. 321-380.

McNamara, D.E., Werner, B.T., 2008. Coupled barrier island-resort model: 1. Emergent instabilities induced by strong human-landscape interactions. J. Geophys. Res., 113(F01016), doi:10.1029/2007JF000840.

Moore, L.J., List, J.H., Williams, S.J., Stolper, D., 2010. Complexities in barrier island response to sea level rise: Insights from numerical model experiments, North Carolina Outer Banks. J. Geophys. Res., 115(F3), F03004.

Morris, J.T., Sundareshwar, P.V., Nietch, C.T., Kjerfve, B., Cahoon, D.R., 2002. Responses of coastal wetlands to rising sea level. Ecology, 83(10), 2869-2877.

Morton, R.A., 2008. National assessment of shoreline change: Part 1: Historical shoreline changes and associated coastal land loss along the US Gulf of Mexico. DIANE Publishing.

Mudd, S.M., Howell, S.M., Morris, J.T., 2009. Impact of dynamic feedbacks between sedimentation, sealevel rise, and biomass production on near-surface marsh stratigraphy and carbon accumulation. Estuarine, Coastal and Shelf Science, 82(3), 377-389.

Murray, A.B., 2003. Contrasting the goals, strategies, and predictions associated with simplified numerical models and detailed simulations. In: R.M. Iverson, P.R. Wilcock (Eds.), Prediction in Geomorphology, AGU Geophysical Monograph 135, Washington, D.C., pp. 151-165.

NAP, 1995. Beach Nourishment and Protection. National Academies Press, Washington, D.C.

Pedersen, J.B.T., Bartholdy, J., 2006. Budgets for fine-grained sediment in the Danish Wadden Sea. Mar. Geol., 235(1-4), 101-117.

Raabe, E.A., Stumpf, R.P., 2016. Expansion of Tidal Marsh in Response to Sea-Level Rise: Gulf Coast of Florida, USA. Estuaries Coasts, 39(1), 145-157.

Rodriguez, A.B., Fegley, S.R., Ridge, J.T., VanDusen, B.M., Anderson, N., 2013. Contribution of aeolian sand to backbarrier marsh sedimentation. Estuarine, Coastal and Shelf Science, 117, 248-259.

Rogers, L.J., Moore, L.J., Goldstein, E.B., Hein, C.J., Lorenzo-Trueba, J., Ashton, A.D., 2015. Anthropogenic controls on overwash deposition: Evidence and consequences. Journal of Geophysical Research: Earth Surface, 120(12), 2015JF003634.

Stolper, D., List, J.H., Thieler, E.R., 2005. Simulating the evolution of coastal morphology and stratigraphy with a new morphological-behaviour model (GEOMBEST). Mar. Geol., 218(1-4), 17-36.

Teal, J.M., Weishar, L., 2005. Ecological engineering, adaptive management, and restoration management in Delaware Bay salt marsh restoration. Ecological Engineering, 25(3), 304-314.

Tebaldi, C., Strauss, B.H., Zervas, C.E., 2012. Modelling sea level rise impacts on storm surges along US coasts. Environmental Research Letters, 7(1), 014032. 
Titus, J.G., Park, R.A., Leatherman, S.P., Weggel, J.R., Greene, M.S., Mausel, P.W., Brown, S., Gaunt, C., Trehan, M., Yohe, G., 1991. Greenhouse effect and sea level rise: the cost of holding back the sea. Coast. Manage., 19(2), 171-204.

Trembanis, A.C., Pilkey, O.H., Valverde, H.R., 1999. Comparison of Beach Nourishment along the U.S. Atlantic, Great Lakes, Gulf of Mexico, and New England Shorelines. Coast. Manage., 27(4), 329340.

Vogel, R.L., Kjerfve, B., Gardner, L.R., 1996. Inorganic Sediment Budget for the North Inlet Salt Marsh, South Carolina, U.S.A. Mangroves and Salt Marshes, 1(1), 23-35.

Walters, D., Moore, L.J., Duran Vinent, O., Fagherazzi, S., Mariotti, G., 2014. Interactions between Barrier Islands and Backbarrier Marshes Affect Island System Response to Sea Level Rise: Insights from a Coupled Model. Journal of Geophysical Research: Earth Surface, 2014JF003091.

Walters, D.C., Kirwan, M.L., 2016. Optimal hurricane overwash thickness for maximizing marsh resilience to sea level rise. Ecology and evolution, 6(9), 2948-2956.

Weinstein, M.P., Teal, J.M., Balletto, J.H., Strait, K.A., 2001. Restoration principles emerging from one of the world's largest tidal marsh restoration projects. Wetlands Ecology and Management, 9(5), 387-407.

Wolters, M., Garbutt, A., Bakker, J.P., 2005. Salt-marsh restoration: evaluating the success of deembankments in north-west Europe. Biological Conservation, 123(2), 249-268. 
Figures:

564
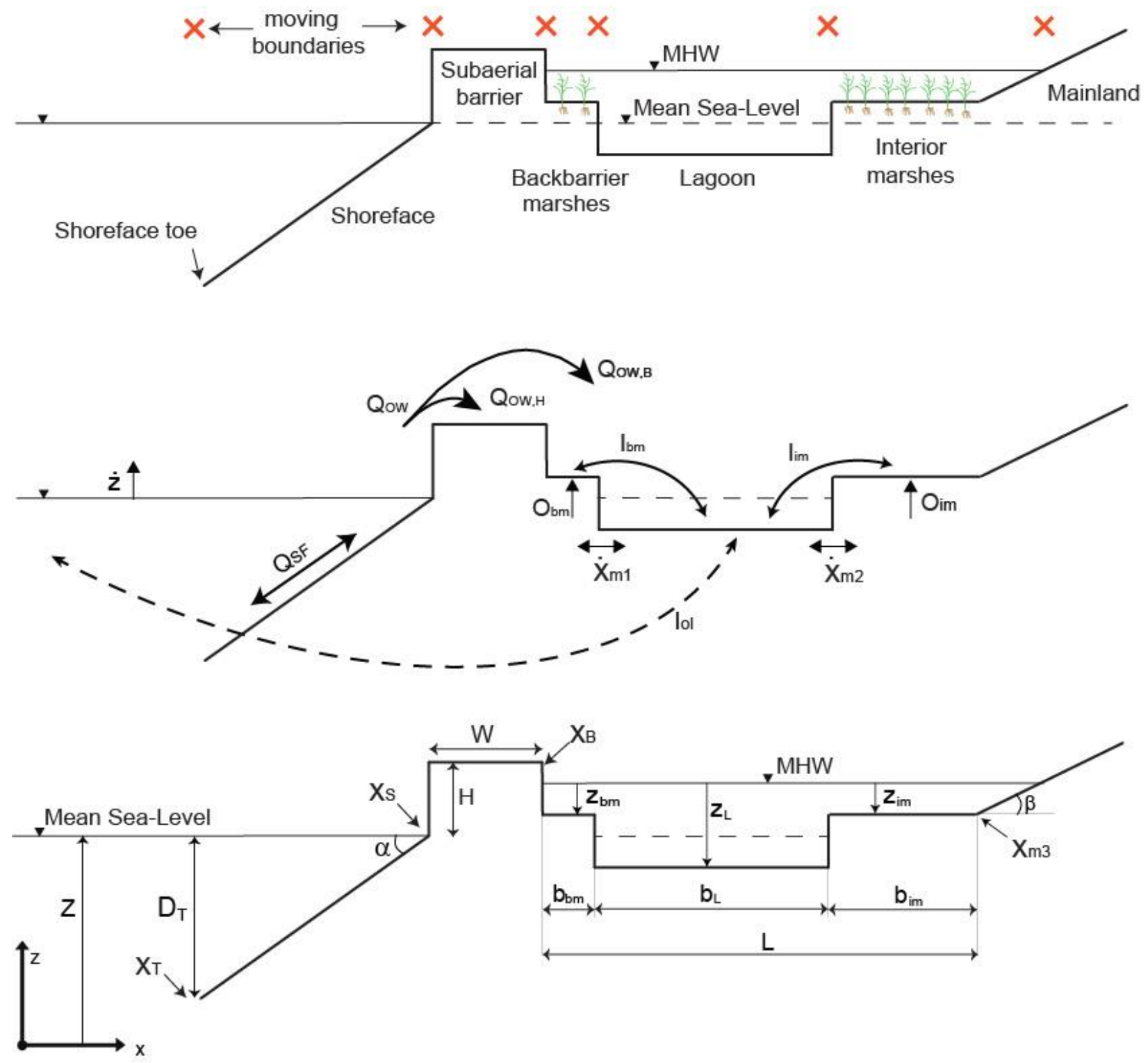

Figure 1. Cross-shore barrier-marsh-lagoon-marsh-mainland model set up, including (a) the different geomorphic domains and their moving boundaries, (b) key processes that drive the evolution of the moving boundaries, (c) state variables. This is the general cross-section of the system, but note that the model can also account for scenarios in which backbarrier and/or inland marshes completely disappear (i.e., $b_{b m}=0$ and/or $b_{i m}=0$ ). 

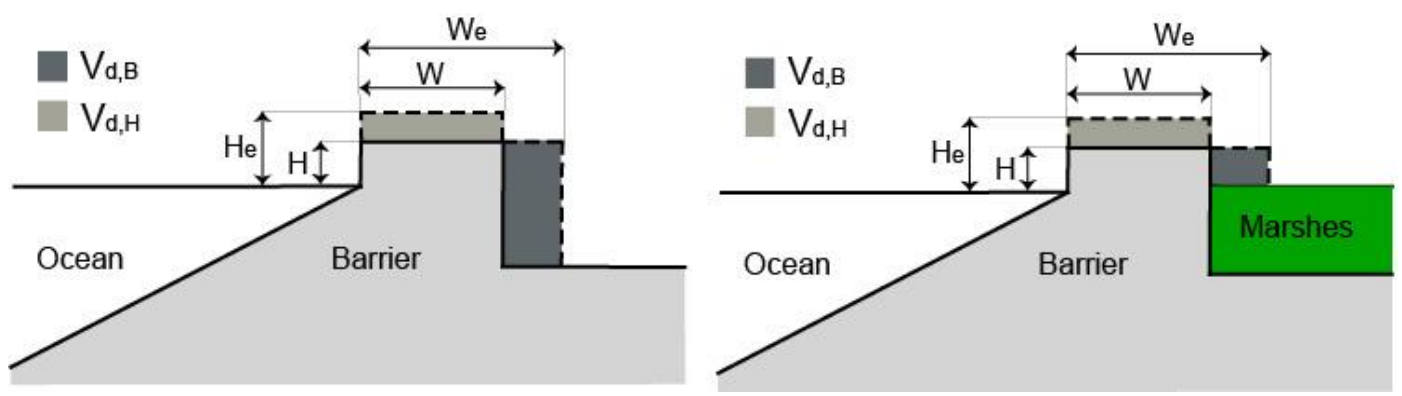

572 Figure 2. Schematic of the critical barrier island width concept and the top-barrier $V_{d, H}$ and back573 barrier $V_{d, B}$ deficit volumes. Note that when backbarrier accommodation is filled by marshes, $V_{d, B}$ 574 is reduced.

579

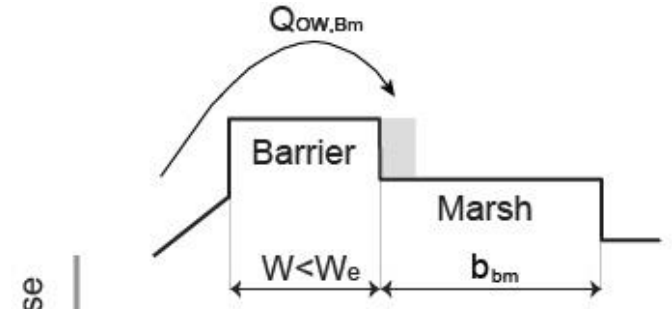

Very wide marsh $\left(\mathrm{b}_{\mathrm{bm}}>\mathrm{b}_{\mathrm{bmc}}\right)$

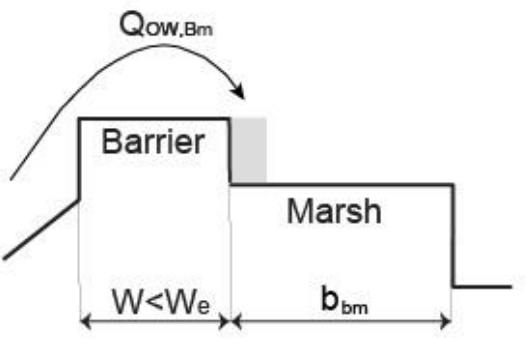

Very wide marsh ( $\left.b_{b m}>b_{b m c}\right)$

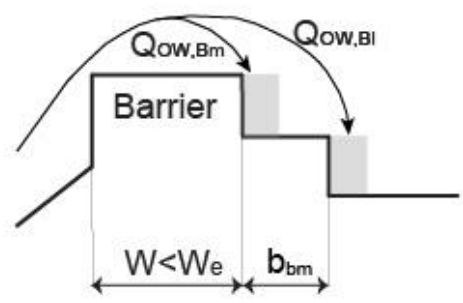

Intermediate marsh width

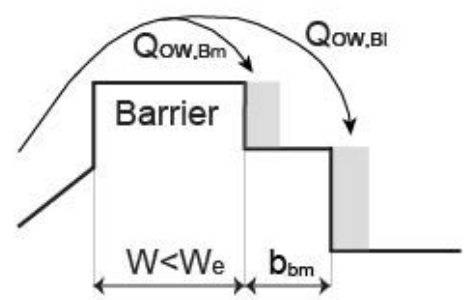

Intermediate marsh width

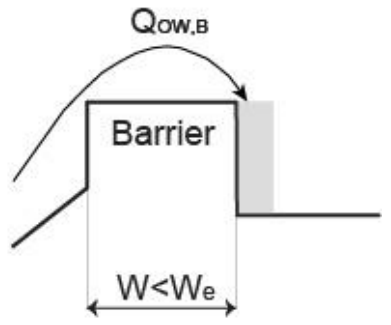

No marsh $\left(b_{b m}=0\right)$

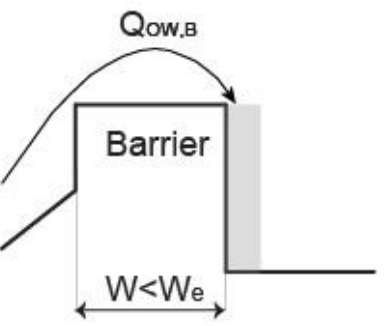

No marsh $\left(b_{b m}=0\right)$

580 Figure 3. Schematic of the backbarrier overwash partitioning between the backbarrier face and 581 the marsh. 

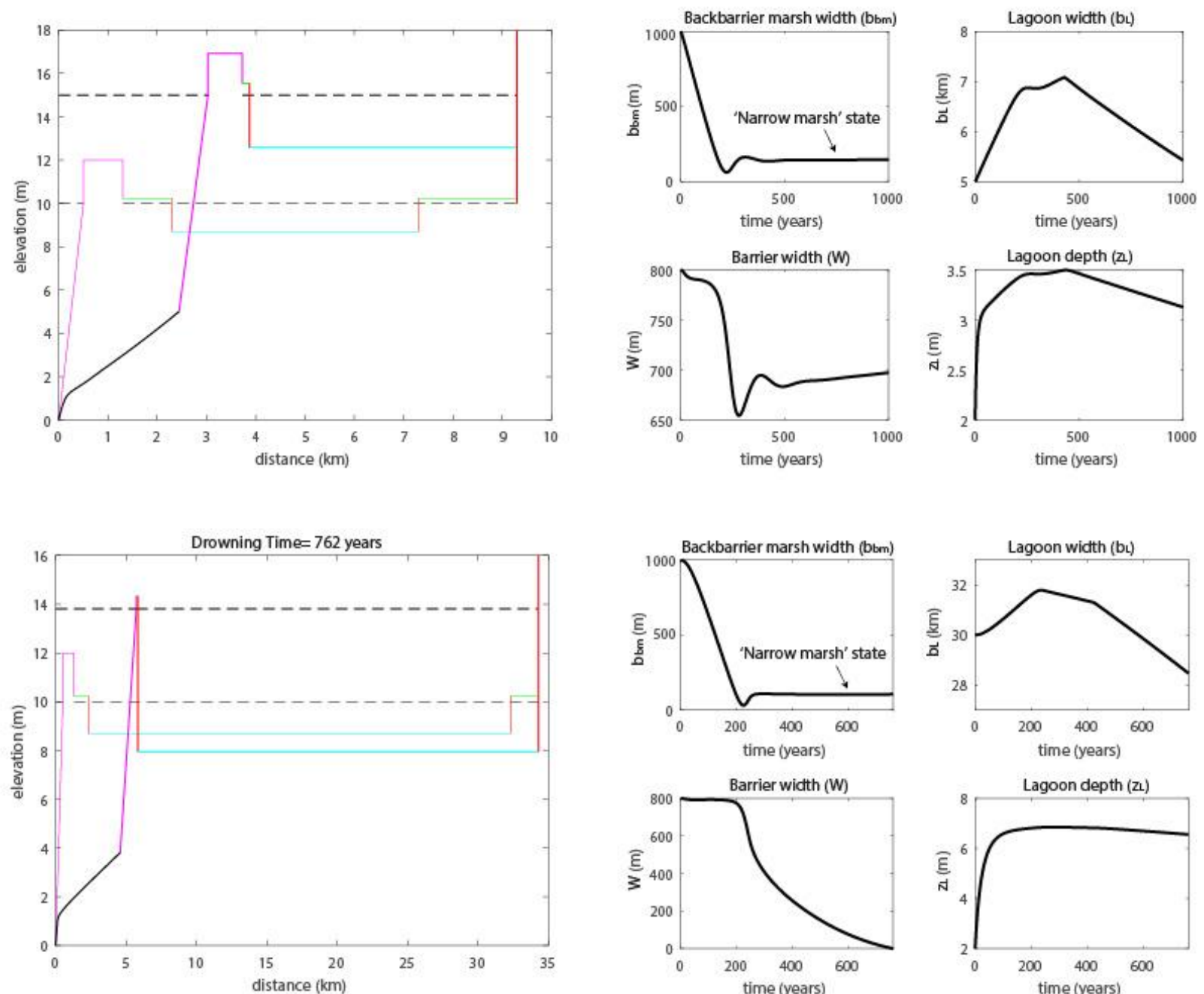

Figure 4. Profile evolution of modelled barrier-backbarrier systems demonstrating the effect of the initial lagoon width $b_{L, 0}$ on barrier response: $b_{L, 0}=5 \mathrm{~km}$ (top), and $b_{L, 0}=30 \mathrm{~km}$ (bottom). Key
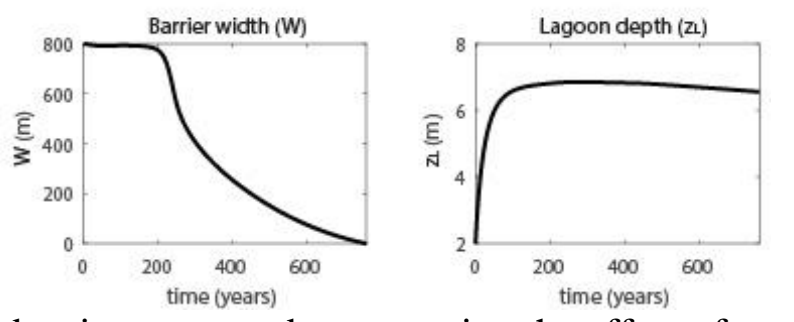

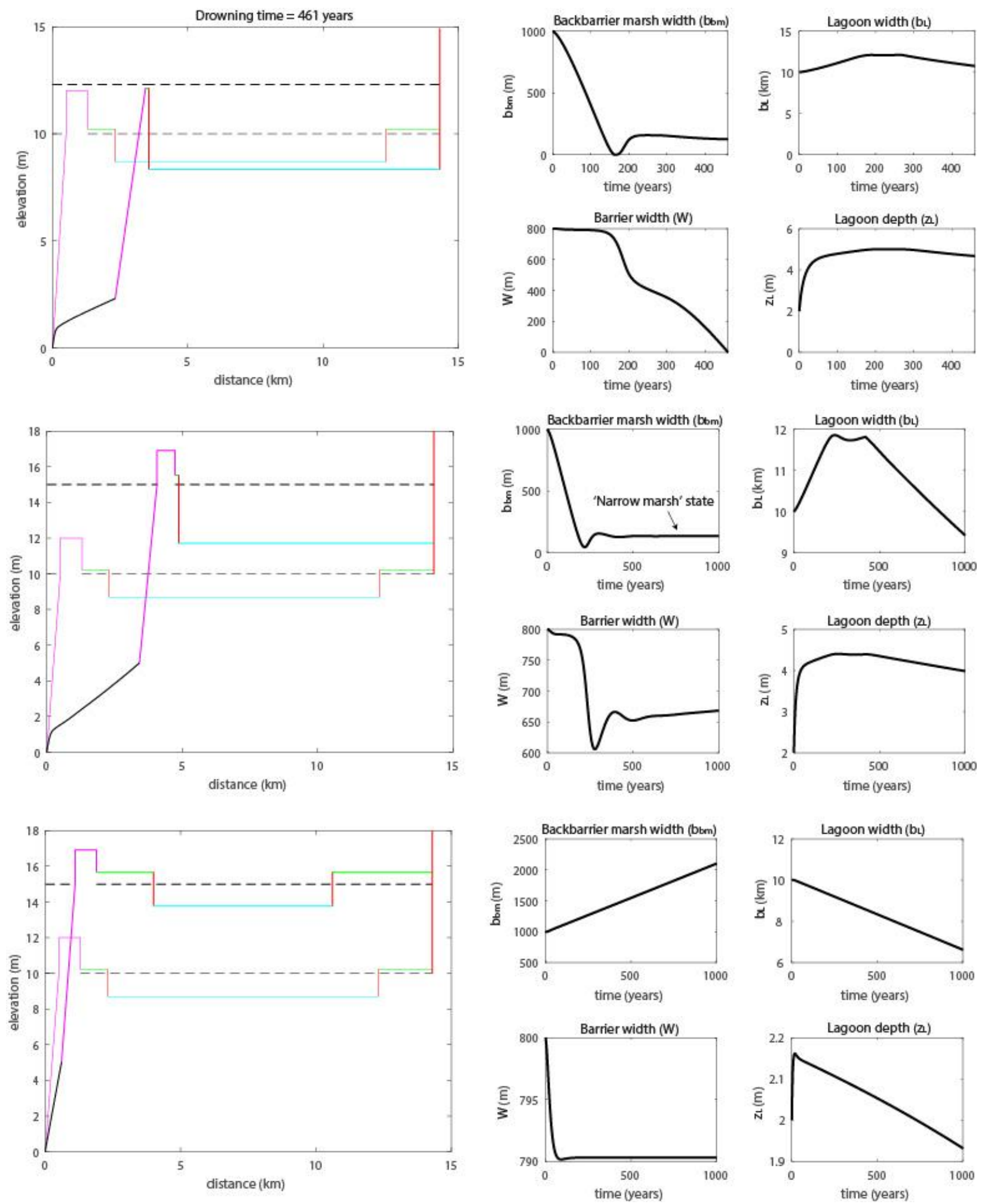

Figure 5. Profile evolution of modelled barrier-backbarrier systems under different rates of sediment exchange with the open sea: net export of sediments with $C_{0}=0 \mathrm{mg} / \mathrm{l}$ (top), mid-scenario 
with $C_{0}=30 \mathrm{mg} / 1$ (center), net import of sediments from the open sea with $C_{0}=200 \mathrm{mg} / 1$ (bottom).

593 Key input parameter values are included in tables 2 and 4 in the appendix.
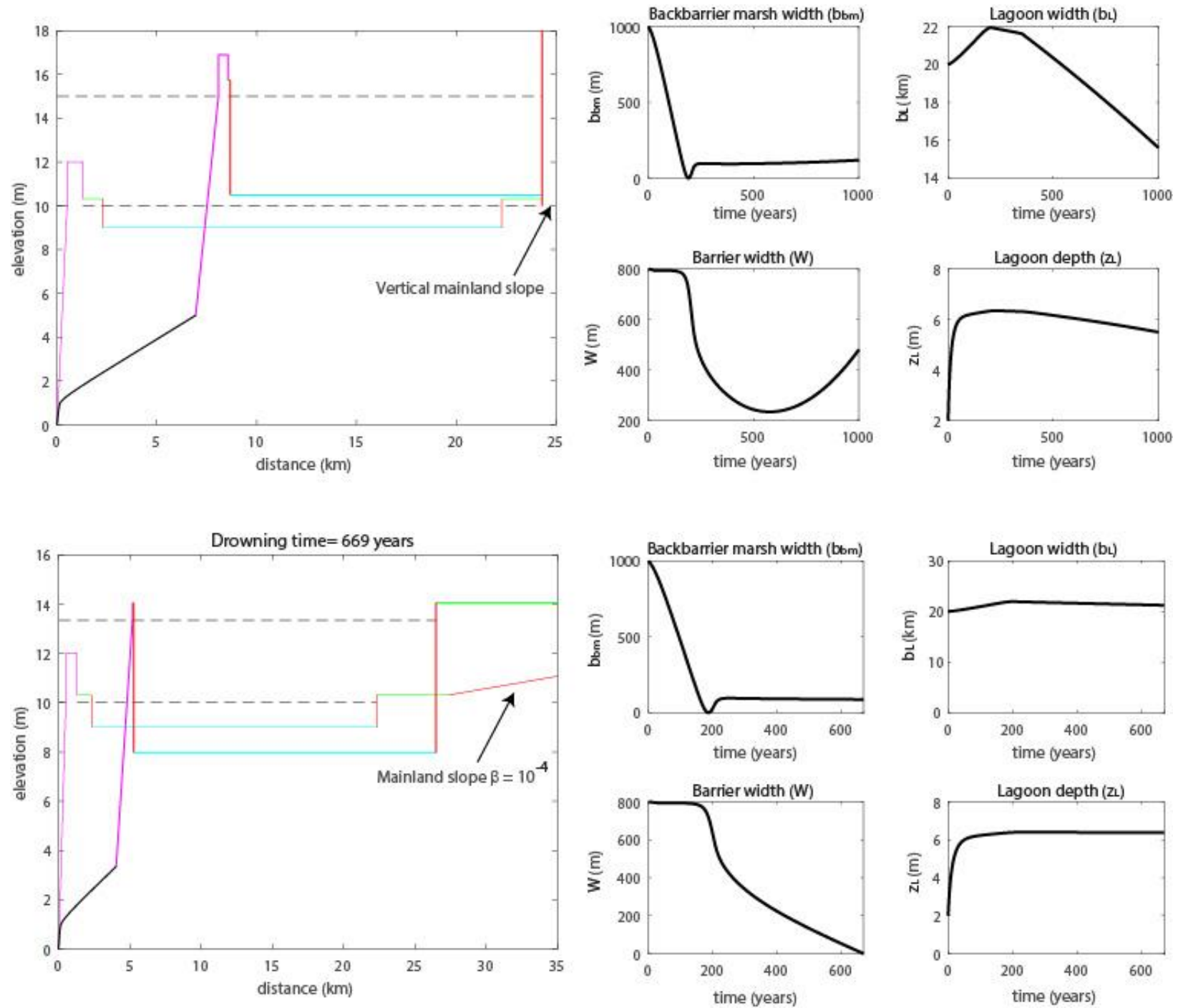

Figure 6. Profile evolution of modelled barrier-backbarrier systems under two different mainland slopes: $\beta=10^{-4}$ (top), and $\beta \gg \gg$ (bottom). Key input parameter values are included in tables 2 and 4 in the appendix.

601

602

603 

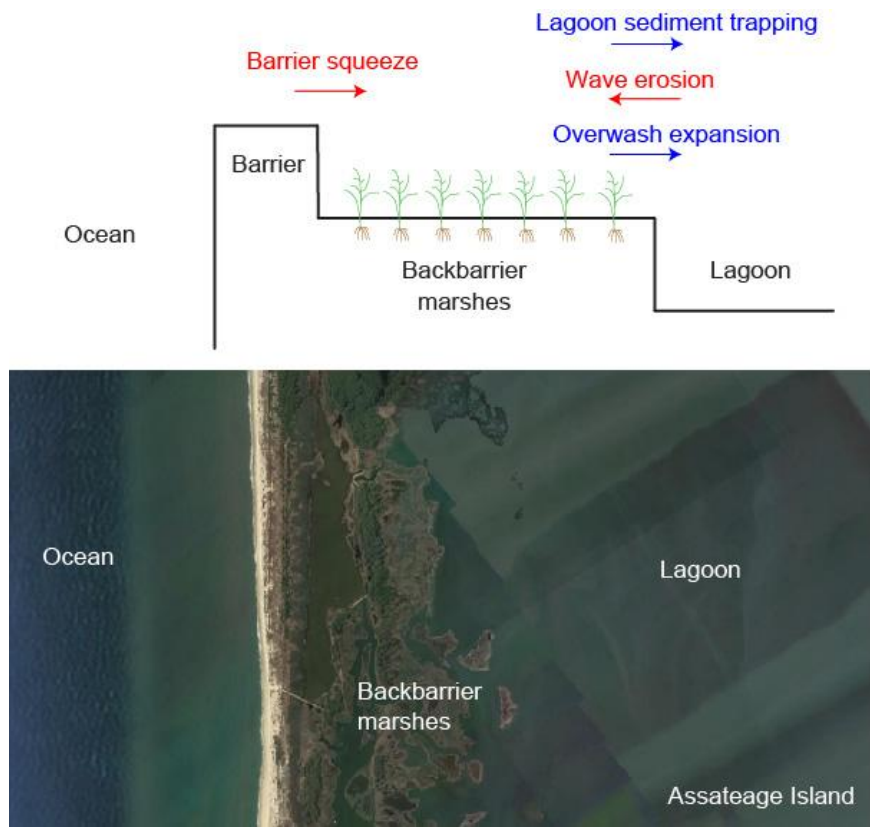

605 Figure 7. The top schematic includes the key processes that control the dynamics of backbarrier 606 marshes. Processes that drive marsh contraction are in red, and those that drive marsh expansion in blue. The bottom photograph of Assateage island, Virginia, illustrate the different 608 environments included in the sketch above. 

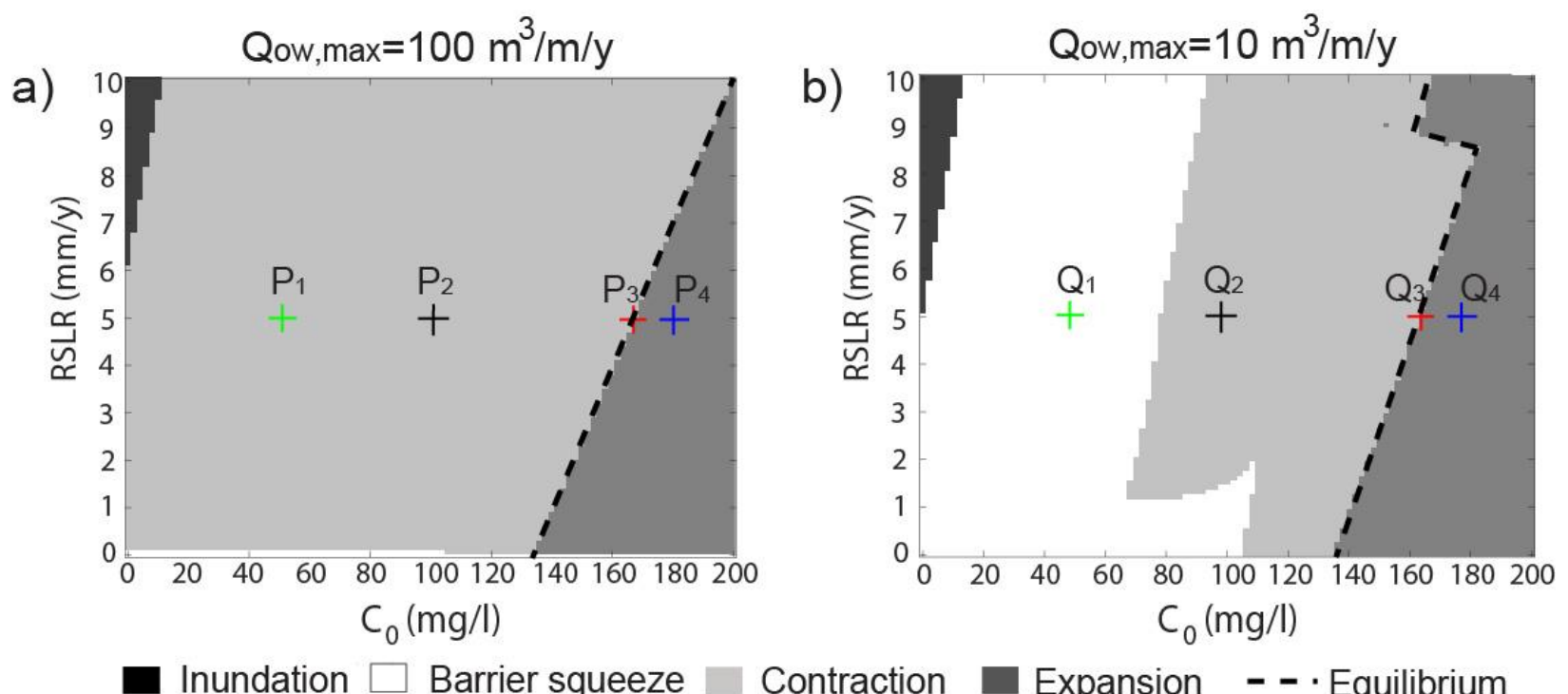

- Inundation $\square$ Barrier squeeze

Contraction Expansion - - Equilibrium
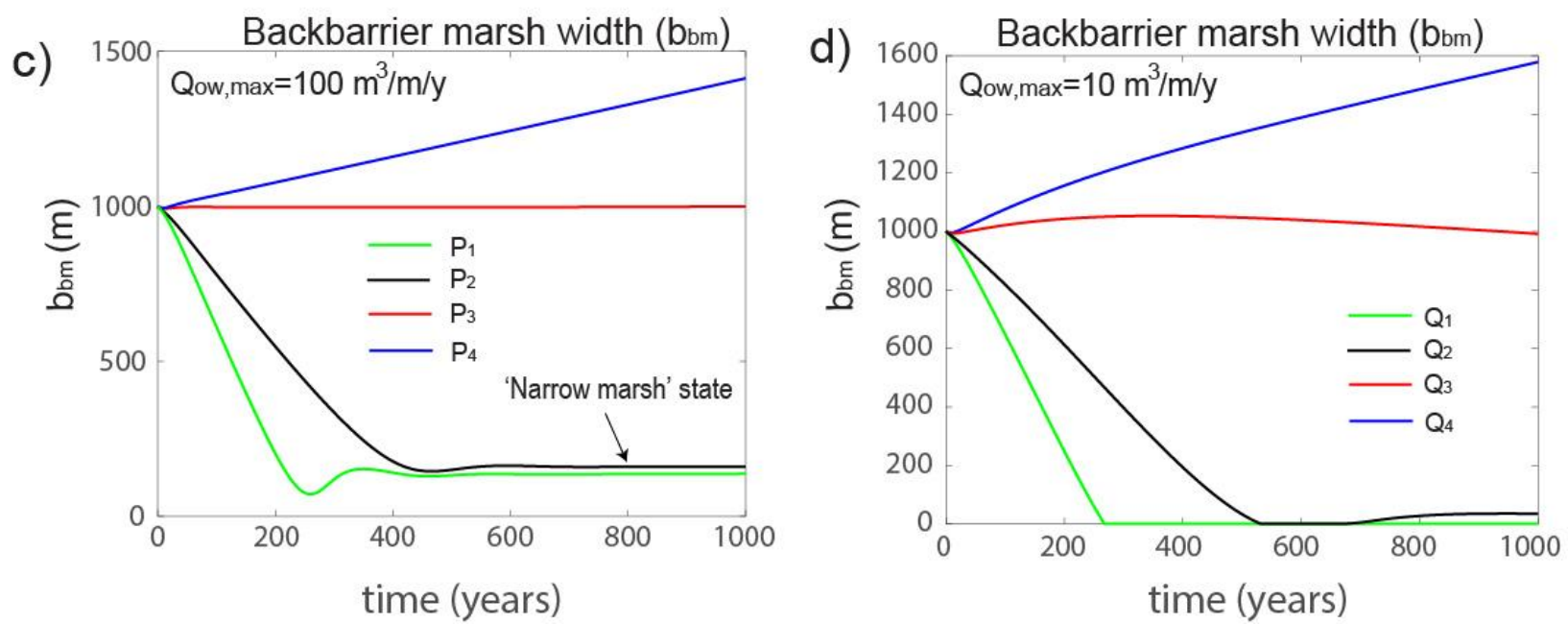

609

610

611

612

613

614

615

616

617

618
Figure 8. Regime diagrams including different system behaviors as sea-level rise rate and the external sediment concentration are varied. The only difference between the two regime diagrams is the maximum overwash flux: (a) $Q_{o w, \max }=100 \mathrm{~m}^{3} / \mathrm{m} / \mathrm{y}$ and (b) $Q_{o w, \max }=10 \mathrm{~m}^{3} / \mathrm{m} / \mathrm{y}$. (c) and (d) depicts the barrier width over time for four different cases in the regime diagrams as indicated. Key input parameter values are included in tables 2 and 4 in the appendix. 